note of the stomach or gas-containing abscess cavity. The fact that the area of tympanitic resonance extended so far to the right was certainly in favour of a distended stomach, but at the time. when viewing the whole features of the case, this did not come out so prominently as on after consideration. Dr. Ewart ${ }^{1}$ lays stress on the occurrence in subphrenic pnenmothorax of an irregular area of tympanitic resonance at the left base of the thorax posteriorly, whilst a distended stomach has a definite convex outline to the left and does not pass into the back. In my case, huwever, the small area of tympanites beyond the stomach to the left over the tenth and and the eleventh ribs was difficult to account for. Lnless, as above suggested, it was due to the mass of new growth behind the stomach no satisfactory reason was found post mortem to explain why the dilated viscus did not descend into the abdomen in the usual way. Lastly, the making of a free opening into the left pleura was undoubtedly a mistake and by causing pneumothorax hastened the fatal termination.

Clitton, Bristol.

\section{CASE OF INTRA-PERITONEAL RUPTURE OF THE URINARY BLADDER; ABDO- MINAL SECTION; SUTURE; RECOVERY.}

BY H. LITTLEWOOD, F.R.C.S. ENG., SURGEOY TO THE GEYERAL IXYIRMARY, IERDS.

SUCCESSFUL cases of suture of the urinary bladder after intra-peritoneal rupture are still of rare occurrence; their rarity and the direct saving of life as the result of an operation make cases of this kind of the greatest interest. The method of treatment adopted in this case was very similar to that carried out in other successful cases. Catgut sutures were used and it was never necessary to pass a catheter after the operation. One of the most important factors in obtaining a successful result in cases of this kind and in all intra-peritoneal catastrophes is undonbtedly an early diagnosis. In this case the operation was performed within 36 hours of the accident.

A man, aged twenty-eight years, was first seen by Mr. W. A. Stott at 10.30 P.M. on Nov. 28th, 1897. The patient went home at about 11 P.M. the previous night and could give no account of himself. He was intoxicated and his clothes were very muddy on his arrival home. He complainer of a good deal of pain in the body throughout the night and the following day, at 10.30 P.M., he was seen by Mr. Stott, who made the following note: "Some abdominal tenderness and signs of fluid in the peritoneal cavity. Pulse 88, soft ; respiration 18 . Catheter passed and $2 \mathrm{oz}$. of urine withdrawn. Patient says he has not passed urine since the previous night." The next day, at 10 A.M., he was again seen by Mr. Stott. There was then some abdominal tenderness. Fluid could easily be detected in the peritoneal cavity and $1 \mathrm{oz}$. of urine was withdrawn by catheter; the temperature was normal and the pulse was 100 . The diagnosis of an intra-peritoneal rupture of the bladder was made. I saw the patient half an hour later, agreed with the diagnosis, and at once made preparations for abdominal section. The operation nas commenced about 11 A.M. Mr. J. Nicholson gave ether and Mr. Stott and one of $\mathrm{my}$ dressers-Mr. A. Spong-assisted me at the operation.

Operation.-An incision about 3 in. long was made in the middle line just abore the symphysis pubis. On opening the peritoneal cavity a large quantity of fluid was found. It was a little turbid and obviously urine. The quantity was not measured, but estimated between 3 and 4 pints. This was rapidly emptied by means of sponges. Some coils of bowel which were seen were inflamed and between some of the coils there were present some flakes of purulent lymph. The rent in the bladder was soon found; it was in the middle line, about $1_{\frac{1}{2}}$ in. in length, and terminated just at the peritoneal reflexion from the top of the bladder. The opening was now easily brought near the surface and closed by means of eight or ten catgut sutures No. 0 , by Lembert's method, including all the vesical coats with the exception of the mucous membrane. The resica wall was thick and appeared quite healthy. It was not thought necessary to test the stitches by distending the bladder. The peritoneum was then carefully sponged, a Bantock's tube was placed in the pelvis, and the abdominal wound was closed. The operation lasted about one hour and the patient did not appear at all collapsed after it.

As to the after treatment, Bantock's tube was emptied frequently during the first twenty-four hours, the quantity of fluid rapidly diminishing, and it was removed at the end of the first forty-eight hours. It was never necessary to use a catheter, as the patient passed urine within six hours of the operation and continued to do so without any difficulty at regular intervals. The temperature was normal after the operation. with one exception-on the evening of Dec. 3rd it reached $99.6^{\circ} \mathrm{F}$. The patient never had a bad symptom; although there was some peritonitis at the time of the operation there was no further development of it after. The patient got up at the end of the third week and since then he has been quite well. He was shown at the clinical meeting of the Leeds and West Riding Medico-Chirurgical Society in March, 1898.

I have to thank Mr. Stott for kindly giring me the notes of the case before and after the operation. Leeds.

\section{ONE HUNDRED AND THIRTY CASES OE RINGWORAI OBSERVED IN THE SKIN DEPARTMENT OF UNIVERSITY COLLEGE HOSPITAL, LONDON.}

\section{By GEORGE PERNET, L.R.C.P. LOND., M.R.C.S. ENG}

SoMe fifty years ago Grüby, ${ }^{1}$ a Viennese doctor, settled in Paris, called attention to the parasitic nature of ringworm of the scalp and beard, and demonstrated the fact that the various clinical forms met with in practice were due to. microscopically distinct fungi. Owing to the nomenclature adopted by him and to the opposition of the Parisian dermatologists of that period, Griby's excellent observations appear to have been practically completely forgotten untill Sabouraud ${ }^{2}$ (1892 and onwards) published the results of his exhaustive investigations, which have been the starting: point of so much work in this and other countries. It is not necessary here to once more go over the ground covered by previous English writers on the subject in the light of recent research. For full details the reader isin referred to their publications. ${ }^{3}$ Shortly, the present views with regard to the fungi causing ringworm are that they are divided into a small-spored (microsporon Audouïni) and a: large-spored (trichophyton megaiosporon) form. The latter is, further subdivided into two classes depending on the situation, of the fungus inside (endothrix) or outside (ectothrix) the hair. To these an endo-ectothrix form is added by some. The main object of the investigation undertaken in the Skin Department of University College Hospital was to ascertain whether these researches were of any practical value as far as treatment and prognosis were concerned. The method pursued was to note the clinical appearances and there and then microscopically examine diseased hairs, stumps, and scales in liquor potassæ B.P. (i.e., about 6 per cent.). In this paper I propose to give a succinct account of the results

1 Grüby : Comptes rendus de l'Académie des Sciences, Paris, 1842 , tome xv., p. 512 ; 1843 , tome xvii., p. 301 ; 1844, tome xviii., p. 583. (The paper published in 1841 referred to favus. Gruby's papers on ringworm fungi are in abstract onl $y$.)

\& Sabouraud: Various papers on the subject from 1892 to the present 2 Sabouraud: Various papers on the subject from 1892 to the present.
time. See especially his beautiful monograph "Les Trichophyties. time. See especially his beautiful monograph

Humaines (Paris, 1894), With an atlas of plates. Adlamson: Observations on the Parasites of Ringworm, British Journal of Dermatology, vol. vii., 1895, pp. 201 and 237, with plates Dolcot Fox and Blaxall: An Inquiry into the Plurality of Fung causing Ringworm in Human Beings as met with in London; ibid., vol. vili., 1896, pp. 242, 291, 337, and 378 (an exhaustive inquiry with Riners aldersmith ( tions (Lewis, London, 1897). Malcolm Morris : Ringworm in the Light of Recent Resti, London, 1898). See also Thin: Patholosy and Treatment of Ringworm (London, 1887); and Leslie Roverts: Introduction to the Mould Fungi, parasitic on Man (Liverpool, 1893). For historical details see also Feulard : Teignes et Teigneux (Paris, 1886). 
of the inquiry, which extended from October, 1896, to May of the present year. It must be understood that they apply to ringworm as observed in the practice of a London hospital.

The 130 cases under discussion were distributed as follows :-

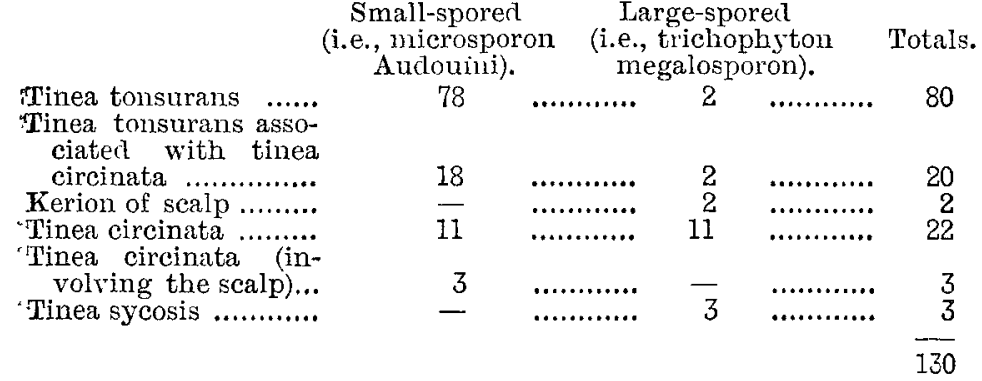

Of the 100 cases of tinea tonsurans and tinea tonsurans associated with tinea circinata, the microsporon Andonini was present in 96 and the trichophyton megalosporon in 4-that is, 24 to 1 . These proportions are, of course, approximate only, as they must necessarily vary within limits. Moreover, the 100 cases recorded did not represent all the cases attending the department during the period mentioned; for various reasons some few patients escaped examination. They may, however, be taken as fairly consecutive. These figures, agreeing on the whole with those of other London observers, show that the very great majority of our cases of ringworm of the wcalp are caused by the small-spored fungus. With regard to the sex of the inicrosporon patients, the males were to the females practically in the proportion of 2 to 1 . As the greater number of the children were of schoolage, this difference in the incidence of the disease may be accounted for by the rougher play of boys, the more srequent interchange of head-gear among them, and the Sact, too, that they wear the hair short. The oldest child was twelve years of age. In about a fifth of the cases of tinea tonsurans due to the small-spored fungus, tinea circinata lesions of the body were also present. The 4 cases of large-spored tinea tonsurans were distributed as follows: two boys, both aged thirteen years, and two girls, aged seven and eight years respectively. In the two girls tinea circinata of the body was also present; one of these patients really first came to the department in 1894; her out-patient's Ietter was renewed in 1897 as the disease was still uncured. The large-spored trichophyton was also found in the two cases of kerion. Both the patients were girls, aged five and eleven years respectively. As to the cases of simple tinea circinata they were practically evenly distributed among the small and the large-spored fungi. One adult, a woman, aged thirty-two years, exhibited the microsporon Audouini (vide infra), and three adults (two women, aged thirty and forty-two years respectively, and one man, aged fifty years) the trichophyton megalosporon. I have placed three cases of tinea circinata in a separate division. They will be referred to under microsporon Audouini. The three cases of ringworm of the beard (tinea sycosis) in which fungus was found belonged to the large-spored group.

Mrcrosporon Audouini: Tinea Tonsurans, including THE Cases IN Which Tinea Circinata Was also Present.

Clinical.-In the untreated cases the diseased areas were circular, more or less scaly, sometimes densely so, dry, with bent, broken, twisted hairs from $\frac{1}{16}$ to $\frac{1}{3}$ of an inch in length growing usually in various directions. Exceptionally the tshort diseased hairs were quite straight, in one instance going off to a point, like an inverted note of exclamation, whilst others in the same patch were bent at an obtuse angle. "The diseased hairs were usually whitish, opaque, with a powdery sheath about their base. This sheath was well marked in a case with a history of three years' duration. In an early case (a boy aged five years with two patches noticed one week) there was scaliness only, but no powdery spore: sheath at the base of the characteristic bent and broken hairs. As a rule the patches were multiple, well-defined, and not inflamed, but slightly reddened only. Many deviations from the type were obseryed, either as a result of long duration, or previous treatment, \&c. In a boy aged six years with multiple patches of twelve months' duration the diseased hairs were whitish, dull, and curled up like wool. In previously treated cases the powdery spore-sheath was often absent. Rarely small bald areas were noticed; in other cases, again, the disease involved nearly the whole of the scalp. One of the latter looked very much like eczema seborrhoicum when first seen. Where tinea circinata was associated with tinea tonsurans the parts affected were usually the face and neck, more rarely the trunk and upper limbs. The patches were sometimes numerous, as in the case of a boy, aged nine years, with tinea tonsurans of the right parieto-occipital region, who had two small scaly patches on the forehead and about a dozen small, pale, fawn-coloured lesions with slight scaly borders about the body. In another, a girl, aged six years, with well-marked, densely scaly patches on the occiput, there were upwards of a score of circinate lesions scattered about the arms and the back of the neck. The majority of these were from $\frac{1}{2} \mathrm{in}$. to $\frac{3}{4}$ in. in diameter, well defined, but solid; the others were in distinct rings, the largest fully $1 \mathrm{in}$. in diameter.

Mricroscopical.-It is important in all cases always to select diseased hairs or stumps. These should be placed on a slicle with a drop of liquor potassæ B.P., and the corerslip gently applied. Where ointments or oily applications have been used it is advisable to first get rid of the fat by placing the specimens in a little ether. (These remarks apply to the large-spored cases as well.) The characteristic feature of the small-spored fungus was the sheath of spores which surrounded the hair for some distance. This spore-sheath extended upwards beyond the intra-follicular portion of the hair. The spores were closely aggregated and fairly equal in size. They were not arranged in any special order, and in this differed from the endo-mycelial spores of the trichophyton megalospcron. They were units crowded together, in this way giving rise to a mosaic appearance. Detached single spores, and spores in twos, threes, and in clumps were seen away from the hair, especially when the coverslip was gently pressed down on the preparation. They were then seen to be round. After a time the sporesheath having been loosened and the spores scattered, the delicate non-sporulated mycelium could be seen within the hair running more or less parallel with it. Where the rootsheath, or part of it, came away with the hair, which was not often the case, the spore-sheath was seen to be situated between the inner root-sheath and the hair itself. The large ghost-like elements mentioned by Adamson" were once noted, but the abundant segmented and sporulated mycelium observed by Fox and Blaxall ${ }^{\circ}$ was never seen. A terminal fringe of mycelial threads towards the rootend was sometimes observed, and was probably due to the intra-pilar mycelium being torn away from the portion of hair left in the follicle. In very early patches of tinea tonsurans mycelium was found in the epidermal scales before the hairs were affected. In one instance abundant branched, granular mycelium (for description of the mycelium see tinea circinata infra) was present in the scales detached with hairs removed from a patch two days old. In the case of one of the hairs there were numerous spores for some distance up and outside the broken proximal end. In another, a couple of mycelial threads were seen penetrating it at the root-end nearly at right angles to the cross section.

\section{TINeA OrRCINATA.}

Clinical. - The lesions due to the small-spored fungus were either small, insignificant, pale scurfy patches, or distinct rings. One or two examples of the latter will be sufficient in this place. In a girl, aged seven years, there was a patch under the left jaw forming a distinct ring with nearly clear centre; she had a similar lesion near the umbilicus. (Her brother, aged three years, seen on the same day, had smallspored ringworm of the scalp.) A woman, aged thirty-two years, who had been bringing her child, aged five and a half years, for diffuse microsporon tinea tonsurans, developed three well-defined circular patches on the flexor surface of the left forearm. They commenced as small irritating pimples which enlarged and spread peripherally. The rings had a raised scaly border and showed signs of slight inflammation. The central portions were depressed and in the case of the two larger patches (nearly half an inch in diameter) scaly. Abundant mycelium of the small-spored kind was found in the scrapings. In three cases in which characteristic small-spored tinea tonsurans was also present some of the circinate lesions exhibited two concentric rings, one within the other. In infants ringworm of the scalp leads, as is well known, to circinate lesions and these may be due to microsporon Audouïni. This appearance was also

4 Adamson: Loc. cit., p. 210.

5 Colcott Fox and Blaxall. (British Journal of Dermatology. Loc. cit., plate II., fig. 4). 
noted in a boy, aged seren years, who had a distinct ring on the left temple. It was about $2 \frac{1}{2}$ in. in diameter, with a slightly red margin, extending quite back into the hairy scalp, the anterior portion alone being on the free skin. There was abundant typical mycelium in the scrapings; mycelium was also present inside one of the broken, bent scalp hairs, but there were no spores outside it. The patient had been using oleate of copper ointment for ten days.

Mioroscopical.-Microsporon Andouini in ringworm of the glabrous parts was present as coarse and irregularly branching mycelium, varying slightly in diameter and greatly in length and shape. The branching usually occurred laterally at right angles to the main filament and the branches were rounded in a sphercidal manner at their free end. (Morphologically, there are some points of resemblance between some of the mycelial elements of achorion Schönleinii (favus), microsporun furfur (tinea versicolor), and microsporon Audouîni as they occur in the human skin.) Further, the mycelium of small-spored ringworm exhibited small refractile dots here and there, which gave it a granular appearaice, but it was not sporulated and was usually unsegmented.

\section{Trichophyton MEgalosporon : Tinea Tonsurans.}

Clinical.-As already stated, four cases only came under observation. The clinical appearances were much less uniform than in the case of the small spored fungus. The patches were not so well defined and appeared to develop more slowly. As a rule they were smaller, varied more in shape, and were but slightly scaly. The stumps were few and far between and required careful looking for. They were, as a rule, broken off short very near or at the level of the scalp, in the latter case presenting the appearance of black dots. They did not exhibit a powdery sheath. The following descriptions from the notes made at the time may be referred to here.

CASE 1. - The patient was a boy, aged thirteen years. The duration of the disease was three months. Several small patches were scattered about the scalp. One in the occipital region was elongated, oval, and almost smooth. $2 \mathrm{in}$. higher up there was a $\frac{1}{4}$ in. scaly patch with a single stump covered by epithelial scales and broken off level with the scalp. In the left posterior parietal region there was a $\frac{1}{4}$ in. totally bare patch. The original patch on the left parietal was about $1 \frac{1}{4}$ in. by 1 in. and ill defined; the stumps were very short, almost level with the skin, and very few in number. On the remaining parts the healthy hair was scanty.

CASE 2.- The patient was a boy, aged thirteen years. The duration of the disease was said to be 14 days (the fact is, the patient, who was dirty and neglected, did not know). There had been no previous treatment. The scalp on the left side, in the posterior half, was to a considerable extent bald. The denudation was incomplete and at the borders was distinctly patchy. Some outlying patches were from $\frac{1}{2}$ in. to $\frac{3}{4}$ in. in diameter. The bald area exhibited here and there a certain amount of ill-nourished but not markedly diseased hair. On the parts which were almost bald there were a few black dots scattered about. There were stumps broken off short, very slightly if at all elevated above the level of the skin, and when removed they were about $\frac{1}{16}$ in. long. A few projected $r^{7}$ in. or more above the surface, but generally broke off when an attempt at epilation was made; a few other hairs were removed and were $\frac{1}{4}$ in. long and slightly curved. Several of the patches were reddened and very slightly crusted, like a subsiding kerion. There were also several bald areas about the scalp, slightly scaly and ill defined. In many of these no stumps could be seen.

Microscopical.-The characteristic feature of the trichophyton was the sporulated and segmented mycelium, or, in other words, the arrangement of the spores in chains. The spores were usually larger than those of microsporon Audouini, but there was much variation in this respect. In Case 2 (vide supra) there were numerous spores forming a sheath round a stump; many were not larger than the spores of microsporon. There was sporulated mycelium inside the hair. Another stump had a few spores external to it. At the broken rootend and in the hair there were chains of spores, the latter rarying very much in size, some being very large; higher up the mycelium was not so markedly sporulated; some, indeed, was not sporulated at all. This appearance led me to conclude that the fungus belonged to the ectothrix group, although there was mycelium in the stumps themselves. ${ }^{6}$ The chains of spores, whether inside (endothrix) or outside (ectothrix), were arranged more or less longitudinally to the diseased hair and the individual spores were more or less square in shape. Where the mycelium was fragile the scattered spores were more oval and rounded. of the four cases Cases 1 and 2 above described were apparently ectothrix (neither of these was associated with tinea circinata) and the other two were apparently endoectothrix (both had in addition tinea circinata patches).

\section{KERION.}

Microscopical.-Two cases only of kerion of the scalp were seen. The patients were girls, aged eleven and five years respectively, and in both large-spored fungus was present. In the latter case the segmented and sporulated mycelium were distinctly ectothrix, but in the former it was apparently confined to the internal portions of the diseased stumps examined.

\section{Tinea Crrcinata.}

Clinical.-Usually the patients exhibited distinct rings with well-marked, raised, red scaly borders. The appearances varied from case to case, especially in the adults. A woman, aged thirty years, had a well-defined patch on the back of one hand. It was slightly papular at the border and somewhat depressed and scaly in the centre. She complained that the back of the hand swelled two or three times a day and became red. When the borders. were scraped for examination there was a little serous exudation. Another woman, aged forty-three years, came with a patch $4 \mathrm{in}$. in diameter on the left forearm. It was papular and papulo-vesicular at the periphery, with here and there small sero-pustular lesions. A man, aged fifty years, had a patch over the knnckles and back of the left hand. The greater part was only reddened, but there were slight excoriation and crusting at the periphery.

Microscopical. - The large-spored fungus in tinea circinata was present in the form of jointed, long, usually straight, dichotomously branching mycelium, which was sometimes sporulated here and there. The segments varied in length, being shorter the nearer they were to the sporulation stage. The width also varied, the filaments being at times very slender. In the case of a male child, aged two years, with tinea circinata of the left cheek, sporulated mycelium was lying curled up in the centre of flattened epithelium cells, arranged in irregularly concentric layers around it; this portion of the preparation was dark in contrast to the clear surrounding epithelium, even after half an hour's soaking: in liquor potassæ. In the case of the woman aged thirty years the mycelium appeared to be attenuated, but it was distinctly divided into equal fairly long segments. On the other hand, in the woman aged forty-two years, where there was marked inflammation, the joints of the mycelium were short and thick (sporulation)

\section{Tinea Srcosis.}

It is not necessary in this place to give a clinical description of the above well-known condition.

Microscopical. - The fungus was not always easy to find and more than one examination of many hairs was sometimest necessary. In the three cases where the search was successful the trichophyton was apparently of the ectothrix kind. Sporulation of the mycelium was the rule, the segments being short and thick.

\section{ETrology.}

Microsporon Audouïni.--In the case of small-spored tinea tonsurans it was usually stated to have been contracted at school or from other children of the same family or in the same house. In several instances the mothers were of opinion the disease had been caught at fever hospitals where the children had been patients (for scarlet fever, \&c.). As this may be the fact-in some cases at least-it would be as well in those institutions to keep children suffering from ringworm apart from the others and to avoid the use of the same combs and brushes. No case could be successfully traced to animals.

Trichophyton megalosporon.-Attempts to trace the disease to animals were also unsuccessful. One of the patients suffering from tinea sycosis was a groom, who stated that some of the horses under his care had suffered from ringworm, but the animals could not be seen. In another case of tinea sycosis, the patient stated that his two birds (a canary and a

6 Colcott Fox and Blaxall : British Journal of Dermatology, loc. cit. p. 296, et seq. 
linnet) were losing their feathers apart from moulting, but no fungus could be found in the feathers subsequently brought to the department. 'The barber's brush was most likely the fons et origo mali in all three cases. In several of the large-spored cases of tinea tonsurans and tinea circinata in children the father was a cabman or a carman; some lived over stables. But this also applied to cases which were distinctly small-spored in character. Moreover, microsporon fungi in the horse and dog have been described. Ringworm in animals is apparently rare in London. Horses are better cared for in London than in Paris ; this may perhaps account for the greater proportion of the large-spored cases in Sabouraud's statistics, assuming that their animal origin be correct.

Treatment and Prognosis.

The differential diagnosis of the large and small-spored fungi does not help us much in London. In the first place, nearly all our cases of ringworm of the scalp belong to the small-spored variety, which is admittedly difficult to cure as a rule, especially in hospital practice. As to the few largespored cases of tinea tonsurans which come under observation some are very obstinate, a fact already noted by several writers, ${ }^{7}$ and confirmed by results obtained at University College Hospital. Nor are treatment and prognosis in tinea sycosis modified by the knowledge that the condition is due to a large-spored fungus. Both the cases of kerion were caused by trichophyton megalosporon and ran the usual course. They could not be compared with kerion cases due to microsporon Audouini. Tinea circinata of the glabrous skin is, as a rule, readily cured, be it of large- or smallspored origin, and need not detain us. Apart from this, however, the question of the plurality of ringworm fungi is an interesting one, but as the scope of this paper is of a practical nature theoretical considerations will not be dwelt upon.

Before concluding I wish sincerely to thank my teacher, Dr. H. Radcliffe-Crocker, not only for placing the cases and notes at my disposal, but for much kindly encouragement during the progress of the inquiry.

\section{CONCLUSIONS.}

1. In a general way my results agreed with those of previous London observers (vide foot-note 3 ). The clinical and microscopical descriptions of Grüby ${ }^{8}$ and Sabouraud ${ }^{9}$ were in the main confirmed. Some points, however, must be more particularly referred to.

2. Small-spored ringnorm.-In the scalp the diseased hairs were usually found growing in various directions. In this I agree with Malcolm Morris and differ from Sabouraud, Adamson, and Colcott Fox, who state that they grow in the direction of the natural set of the hair. Small-spored kerion did not come under my observation. Adamson, Fox and Blaxall, and Morris have met with it in London. Opinions differ as to the mode in which the hair is attacked. I have seen the mycelium of the small-spored fungus invading a hair at its root end. 'This is not in accordance with Sabourand. I agree with Adamson and Fox that the fungus is in the epidermis before the hairs are affected. It appears to me to be natural that it should be so ; but Sabouraud and Morris hold a contrary opinion. The abundant segmented and sporulated mycelium depicted by Fox and Blaxall 10 was never seen by me in the case of microsporon Audouini of the scalp. On the body the lesions were sometimes in distinct rings, with a well-defined border and somewhat depressed centre; moreover, the border was frequently decidedly reddened and even slightly inflamed. This also does not agree with Sabouraud's original descriptions. In the series under consideration small-spored tinea circinata was as frequent as tinea circinata due to largespored fungi. The view generally held is that nearly all the cases are of the latter kind. In adults this is certainly the case, but not in children. Moreover, small-spored tinea tonsurans may be associated with multiple small patches and rings on the body and limbs, but this is a rare occurrence. This again does not agree with Sabouraud's rule. The microsporon form of scalp ringworm appeared to be more contagious than that of megalosporon origin. This agreed with Sabouraud's Parisian experience.

3. Large-spored ringrorm. - In tinea tonsurans the diseased hairs are usually broken off at or near the level of

H. Radeliffe Crocker: Diseases of the Skin, second edition, p. 815 , Aldersmith : Op. cit., p. 60 , et seq. Colcott Fox: British Journal of
Dermatology, July, 1898 , p. 253 . 8 Loc. cit. $\quad 9$ Loc. cit.

10 Loc. cit. the scalp, but occasionally they are found projecting beyond the level of the scalp. This form is not always readily cured. It may be very obstinate and resist treatment for several years, a fact already noted by other London observers ( $H$. Radcliffe-Crocker, Aldersmith, and Fox), but which does not agree with Sabouraud's Paris experience. The clinical appearances both in the scalp and on the body vary. This polymorphism has been insisted on by Sabouraud and confirmed in the case of London. The two cases of kerion belonged to this group and so far confirm Sabourauc's view, but whether they were derived from the horse could not be ascertained; the father of one of the patients was a carman. In tinea sycosis the fungus is not readily found. It may escape detection altogether where suppuration is well marked and when repeated examinations of many hairs are not made. This is generally admitted. The varieties of trichophyton megalosporon (endothrix, ectothrix, and endo-ectothrix) could not always be differentiated with certainty by microscopical examination.

4. Relative frequency of large- and small-spored tinea tonsurans.-My figures-viz., 96 small-spored to 4 largespored-agree closely with Adamson's (178 to 5). Morris states that microsporon Audouini is responsible for about 90 per cent. Fox and Blaxall give from 80 to 90 per cent., taking all ringworms (scalp, body, beard).

5. Etiology.--In no single case was it possible to demonstrate an animal origin. Several of the cases of tinea tonsurans had apparently been contracted in fever hospitals.

6. Diagnosis. - The differential diagnosis of large- and small-spored ringworm could usually be arrived at on clinical grounds alone and nearly always confirmed by a microscopical examination.

7. Treatment and proynosis.-With regard to these two points it is practically "as you were," for the two reasons already given, viz. : (1) nearly all the London cases of ringworm of the scalp (which alone concerns us here) are smallspored, which are admittedly obstinate; and (2) of the remaining rare large-spored cases some are extremely resistant to treatment.

Upper Gloucester-place, N.W.

\section{A CASE OF TYPHOID FEVER IN WHICH A FATAL ISSUE FROM EXTREMIE TYMPANITES WAS AVERTED BY PUNCTURE OF THE TRANSVERSE COLON.} BY J. W. DALGLIESH, M.D. DeRH.

THE patient was a man, aged about thirty years. He was first seen by me on Sept. 29th, 1896, and had then been ailing for four days. He complained of severe headache, giddiness, lassitude, bleeding from the nose, free perspiration, and inability to sleep. His temperature was $103^{\circ} \mathrm{F}$. His tongue was furred and injected. When he was admitted to hospital on Oct. 1st typical spots were seen on the abdomen and chest. On the 2nd there were tympanites and colicky pains. He undoubtedly had peritonitis. On the 4th romiting and diarrhoea were present. On the 7 th the tympanites was most extreme, displacing the heart and interfering with its action. The apex beat was well above, and to the left of, the left nipple. The pulse was very frequent, irregular in time and force, intermittent, small and short, and devoid of tension. The patient's countenance was drawn, haggard, and pinched, and there were stupor and picking at the bedclothes with muttering delirium. The tonoue was dry, raw, and beefy. The temperature was $104.4^{\circ}$ and he appeared to be sinking fast. The administration of turpentine by the mouth was useless. Opium had already aggravated the condition. The passage of a long tube up the rectum led to the most tremendous evacuation of typical pea-soupy fluid which was horribly offensive, but no relief was obtained. Could more be done? The transverse colon was beautifully delineated, running across the abdomen in a very distended state. I boldly pushed a Southey's trocar and cannula into it. On withdrawing the trocar much gas escaped with a loud hissing noise for two minutes. At once there was great 